\title{
Monostotic Fibrous Dysplasia of the Temporal Bone: A Case Report and Review of the Literature
}

\author{
Ilson Sepulveda ${ }^{\mathrm{a}, \mathrm{e}}$, J. Patricio Ulloa ${ }^{\mathrm{b}}$, Romina Novoa ${ }^{\mathrm{c}}$, Rodrigo Barros ${ }^{\mathrm{d}}$
}

\begin{abstract}
Fibrous dysplasia (FD) is a rare osseous pathology of unknown origin in which normal bone is replaced by fibro-osseous tissue. Recent research has linked FD to a somatic mutation in the protein transcription of the GNAS1 gene, which leads to an increase in intracellular cyclic adenosine monophosphate. FD represents $2.5 \%$ of all bony tumors and over $7 \%$ of all non-malignant bone tumors. FD has various clinical presentation groups such as the monostotic, craniofacial and polyostotic forms, and the McCune-Albright syndrome. We present a temporal bone monostotic FD case of a 66-year-old female patient, who underwent surgical treatment of pituitary tumor.
\end{abstract}

Keywords: CT; Fibrous; Dysplasia; Monostotic; Temporal; Bone

\section{Introduction}

Fibrous dysplasia (FD) is a relatively rare osseous disease of unknown etiology, where the normal bone is changed by fibrous tissue, bony metaplasia and newly formed poorly calcified bone. The majority of FD cases are found between 10 and 30 years old, have the same prevalence rate in males and females and show variable radiographic features in relation with the level of maturation, which determines of the imaging characteristics. FD can be monostotic or, more rarely, polyostotic. This case is of particular interest due to the late presentation as an incidental finding, considering that this entity is more commonly seen in the first two decades of life.

Manuscript submitted September 28, 2018, accepted October 8, 2018

aFinis Terrae University School of Dentistry; Radiology Department, ENTHead and Neck Surgery Service, General Hospital of Concepcion, Concepcion, Chile

bENT-Head and Neck Surgery Service, General Hospital of Concepcion; University of Concepcion School of Medicine, Concepcion, Chile

${ }^{c}$ ENT-Head and Neck Surgery Service, General Hospital of Concepcion; Resident University of Concepción School of Medicine, Concepcion, Chile

${ }^{\mathrm{d} E m e r g e n c y ~ a n d ~ I n t e r n a l ~ M e d i c i n e ~ S e r v i c e s, ~ G e n e r a l ~ H o s p i t a l ~ o f ~ C o n c e p c i o n, ~}$ Concepcion, Chile

${ }^{\mathrm{e} C}$ Corresponding Author: Ilson Sepulveda, ENT-Head and Neck Surgery Service, General Hospital of Concepcion, San Martin Av. 1436, Concepcion, Chile. Email: isepulvedaa@uft.edu

doi: https://doi.org/10.14740/jmc3180

\section{Case Report}

A 66-year-old female, with medical history of pituitary macroadenoma treated with surgery in 2017, in periodical control, gave no history of hearing loss, pain or tinnitus. Post-surgical high-resolution CT scan demonstrated a focal expansion of the left petrous temporal bone with complete sclerosis of the mastoid air cells. The middle ear cavity, ossicles and external canal were uninvolved. In comparison, the right temporal bone appears well pneumatized with no apparent abnormalities. Diagnosis of monostotic fibrous dysplasia was made based on the above findings (Figs. 1, 2).

After evaluation, the Ear Board mainly recommended periodic control and will offer possible surgical treatment if her hearing becomes further impaired or develops an obstructive symptoms.

\section{Discussion}

FD is a rare condition and non-inherited osseous pathology of unknown origin where the normal bone is superseded by fibro-osseous tissue. FD represents $2.5 \%$ the bone lesion and

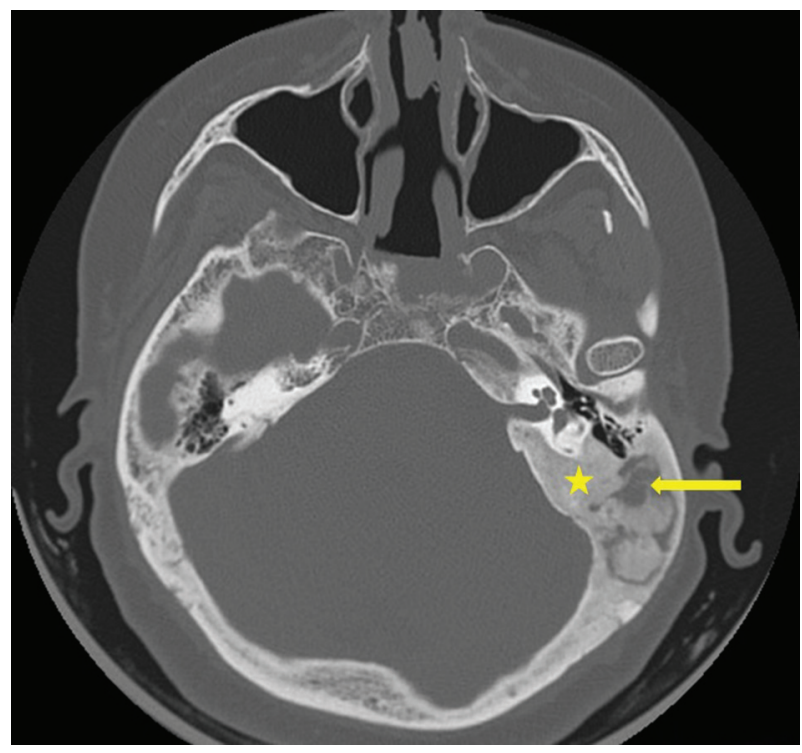

Figure 1. CT scan, bone window and axial view, showing bony overgrowth involving the left temporal bone (yellow star) with sclerosis and lytic changes within the mastoid air cells (yellow arrow). 


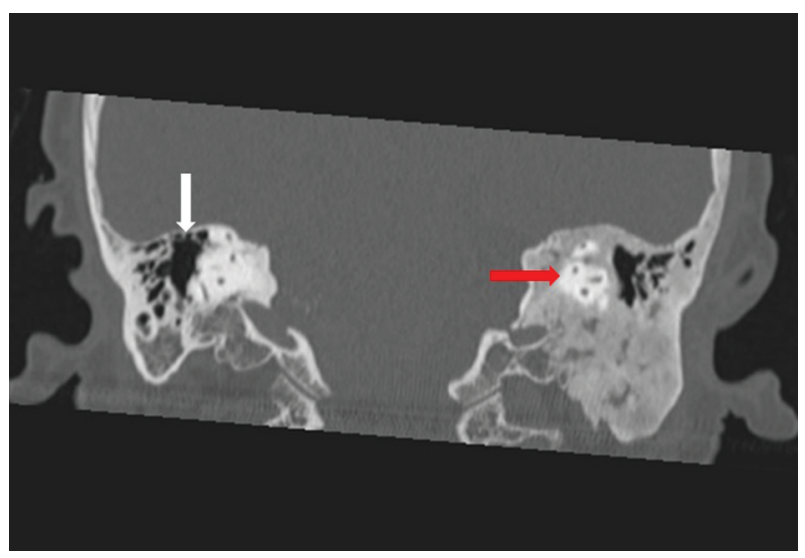

Figure 2. CT scan, bone window and coronal view, showing uninvolved semicircular canals (red arrow). The right temporal bone appears normal (white arrow).

$7 \%$ of benign bone tumors [1]. It was first described by McCune and Bruch and Albright et al in two different articles in 1937 [2]. FD has various clinical presentation groups such as the monostotic $(70 \%)$, polyostotic $(30 \%)$ and the McCuneAlbright syndrome (3\%) [3]. More frequently, the FD was observed in patients between 10 and 30 years old, and the distribution rate between male and female is $2: 1$. A race predilection has been observed, with Caucasians comprising $80 \%$ of all cases, African-Americans 2\% and Asians 1\% [4]. The McCune-Albright syndrome is more common in females [5].

FD and McCune-Albright syndrome arise from activating missense mutations of the GNAS gene, which encodes the $\alpha$-subunit of the Gs stimulatory protein (Gs $\alpha)$. Mutations which occur post-zygotically resulting in a mosaic pattern of disease were shown to dramatically upregulate RANKL expression, consistent with the increased levels of osteoclastogenesis (RANKL promotes osteoclast differentiation and ultimately leads to increased bone resorption) $[6,7]$.

Polyostotic FD affects many bones usually on the ipsilateral side of the body, is relatively rare, and in some cases, is called the Jaffe type. When the polyostotic form of FD, cutaneous pigmentation and no regulated hyperfunction of one or many endocrine glands are observed, we find the presence of McCune-Albright syndrome [8-10].

Craniofacial involvement is found in only $10 \%$ of cases of the monostotic variety with the following order of involved bones: frontal, sphenoid, ethmoid, maxillary, mandible, zygomatic, occipital and temporal. Temporal bone involvement is very rare, with less than 60 cases being reported in the literature $[11,12]$. It usually involves the external auditory canal, although it may also involve the middle ear, jugular foramen and more rarely, extend into the otic capsule [13].

The patient's symptoms aligned with the location of the lesion, led by atypical facial pain, headache, nerve compression and sinus symptoms. In the case of FD in the temporal bone, the most reported clinical findings are conductive hearing loss and obstruction of the external auditory canal [12].

Barrionuevo et al classified fibrous dysplasia of the temporal bone into the following three stages according to the progression of the disease: stage 1, latent phase; stage 2, sympto- matic phase; and stage 3, complication phase [13].

High-resolution $\mathrm{CT}$ is the examination of choice if fibrous dysplasia is highly suspected. Homogenous ground-glass density, loss of the trabecular pattern and asymmetrical thickening of the cortical wall are the typical manifestations. CT attenuation coefficient values vary between 34 and 513 Hounsfield units in the different series, in relation with the amount of fibrous and osseous tissue and the rate of bone deposition, leading to three major imaging patterns: pagetoid (56\%), sclerotic $(23 \%)$ and cystic $(21 \%)$ types [14-17].

The differential diagnosis of bony lesions of the temporal bone includes Paget's disease, which presents with diffuse involvement of the temporal bone and calvarium. Ossifying fibromas, which have a well-demarcated border on CT imaging, can also mimic the cystic pattern of fibrous displasia [18]. The rate of variation to malignant tumor is higher in monostotic craniofacial disease $(0.05 \%)$. Osteosarcoma, fibrosarcoma and chondrosarcoma are the most prevalent malignant tumors reported in the literature [9].

Conservative treatment is recommended initially depending on the extent of the disease, the patient disability experienced as a result of the hearing loss and surgeon expertise. Middle ear exploration and/or tympanomastoidectomy may be needed to manage extension of the disease into the middle ear and mastoid cavity or to manage complications such as colesteatoma [19].

\section{Conclusions}

Monostotic FD of the temporal bone is rare, has no symptoms or may present with different neurological signs. The diagnosis depends mainly on the imaging exams (X-ray, CT or CBCT), but clinicians must be aware of the potential diagnosis even if no symptoms are observed. The treatment, in most cases, is conservative; surgery is only indicated in cases of the patients who develop complications, oto-neurological symptoms or improve cosmetic demands.

\section{Conflict of Interest}

The authors declare no conflict of interest.

\section{References}

1. Couturier A, Aumaitre O, Gilain L, Jean B, Mom T, Andre M. Craniofacial fibrous dysplasia: A 10-case series. Eur Ann Otorhinolaryngol Head Neck Dis. 2017;134(4):229235.

2. Mallina S, Philip R, Chong AW, Gurdeep S. Fibrous dysplasia of the temporal bone. Med J Malaysia. 2007;62(2):160161.

3. Chinski A, Beider B, Cohen D. Fibrous dysplasia of the temporal bone. Int J Pediatr Otorhinolaryngol. 1999;47(3):275281.

4. Song JJ, Jung HH, Lee HM, Hwang SJ. Monostotic fibrous dysplasia of temporal bone: report of two cases 
and review of its characteristics. Acta Otolaryngol. 2005;125(10):1126-1129.

5. Clark J, Carson W. A case of craniofacial polyostotic fibrous dysplasia. J Radiol Case Rep. 2010;4(9):1-6.

6. Orhan K, Icen M, Paksoy CS, Arslan A, Oztas B. Frontoorbital sphenoethmoidal fibrous dysplasia. Oral Radiol. 2009;25:135-141.

7. Boyce AM, Chong WH, Yao J, Gafni RI, Kelly MH, Chamberlain CE, Bassim C, et al. Denosumab treatment for fibrous dysplasia. J Bone Miner Res. 2012;27(7):14621470 .

8. Caia MJ, Maa LT, Xua GZ, Gruenb P, Lia J, Yanga M, et al. Clinical and radiological observation in a surgical series of 36 cases of fibrous dysplasia of the skull. Clinical Neurology and Neurosurgery. 2012;114:254-259.

9. Celenk P, Zengin Z, Muglali M, Celenk C. Computed tomography of cranio-facial fibrous dysplasia . European Journal of Radiology Extra. 2009;69:85-87.

10. Chen Y, Ding X, Yang Y, Yan W, Chen D, Li Z. Craniofacial fibrous dysplasia associated with McCune-Albright syndrome. J Oral Maxillofac Surg. 2009;67(3):637-644.

11. Yang H, Chen S, Zheng Y, Xu Y, Zhang X, Xiong H, Zhang Z, et al. Surgical treatment of monostotic fibrous dysplasia of the temporal bone: a retrospective analysis. Am J Otolaryngol. 2012;33(6):697-701.

12. Pineker V, Marques Maggio E, Huber A, Pangalu A, Valavanis A, Winklhofer S. Rare appearance, rare location and unusual patient age : report of osteolytic fibrous dysplasia in the temporal bone of a 52-year-old patient. Clin Neuroradiol. 2017;27(4):521-524.

13. Kimitsuki T, Komune S. Asymptomatic fibrous dysplasia of the temporal bone. J Laryngol Otol. 2015;129(Suppl 2):S42-S45.

14. Liu YH, Chang KP. Fibrous dysplasia of the temporal bone with external auditory canal stenosis and secondary cholesteatoma. J Int Adv Otol. 2016;12(1):125-128.

15. Abdelkarim A, Green R, Startzell J, Preece J. Craniofacial polyostotic fibrous dysplasia: a case report and review of the literature. Oral Surg Oral Med Oral Pathol Oral Radiol Endod. 2008;106:49-55.

16. Cappabianca S, Colella G, Russo A, Pezzullo M, Reginelli A, Iaselli F, Rotondo A. Maxillofacial fibrous dysplasia: personal experience with gadoliniumenhanced magnetic resonance imaging. Radiol Med. 2008;113(8):1198-1210.

17. Yadavalli G. Fibro-osseus lesions of the jaw: a report of two cases. Journal of Clinical Imaging Science. 2011;1(1):1-5.

18. Jethanamest D, Roehm P. Fibrous dysplasia of the temporal bone with complete canal stenosis and cholesteatoma. Otol Neurotol. 2011;32(7):e52-53.

19. Fandino M, Bhimrao SK, Saxby AJ, Dar Santos RC, Westerberg BD. Fibrous dysplasia of the temporal bone: systematic review of management and hearing outcomes. Otol Neurotol. 2014;35(10):1698-1706. 